\title{
Comparing SSI In Purse-String Versus Conventional Primary Closure Following Stoma Reversal
}

\section{Sabih Nofal, ${ }^{1}$ Anum Arif, ${ }^{2}$ Ahsan Khan, ${ }^{3}$ Sundus Saif, ${ }^{4}$ Abdul Waheed Khan, ${ }^{5}$ Muhammad Arif ${ }^{6}$}

\begin{abstract}
Objective: To compare the frequency of Surgical Site Infection ( SSI ) and mean length of hospital stay between the Purse-string closure and conventional primary closure techniques for stoma reversal.

Methods: The study was carried out in Surgical Unit-III, Lahore General Hospital Lahore from January 5, 2018 to July 5, 2018. The study designed as a Observational Study. Patients undergoing surgery for Ileostomy were randomly divided into two groups, Group-A(Purse-string closure) and Group-B (Conventional primary closure). All the patients were called for follow up checkup on 14th days after operation and after one month. Both of the groups were checked and recorded for SSI after operation and hospital stay. The data was statistically analyzed by using SPSS v23.0.t test (independent sample) used for the comparison of hospital stay mean. Chi-square was also used for the comparison of the frequencies of SSI. Data were stratified for gender and age. A p-value $\leq 0.05$ was considered as significant.

Results: A total of 140 patients were enrolled for this study. Patients were divided into two groups i.e. GroupA(Purse-string closure) and Group-B (Conventional primary closure). In group-A, mean duration of hospital stay was $5.7 \pm 1.0$ days, while $7.3 \pm 1.1$ days in group-B, which is statistically significant with a $p$-value of 0.000. In group-A, surgical site infection was in 4(5.7\%) patients, while 11(15.7\%) patients of group-B, which is statistically significant with a $p$-value of 0.046 .

Conclusion: The frequency of surgical site infection and mean length of hospital stay after stoma reversal, purse-string suturing technique is significantly less than conventional primary closure technique.

Key Words: Surgical stoma; Ileostomy; Closure; Infection.

How to cite: Nofal S., Arif A., Khan A., Saif. S., Khan W.A., ArifA. Comparing SSI in Purse-String Versus Conventional Primary Closure Following Stoma Reversal. Esculapio 2021; 17(01): 15-19

DOI: https://doi.org/10.51273/esc21.251713
\end{abstract}

\section{Introduction}

$\mathrm{I}$ $\mathrm{n}$ colorectal surgery it is properly known that anastomotic leakage is an main problem and complication, specially in coloanal anastomosis and low colorectal. The momentary defunctioning stoma may decrease the re operative rate and anastomotic

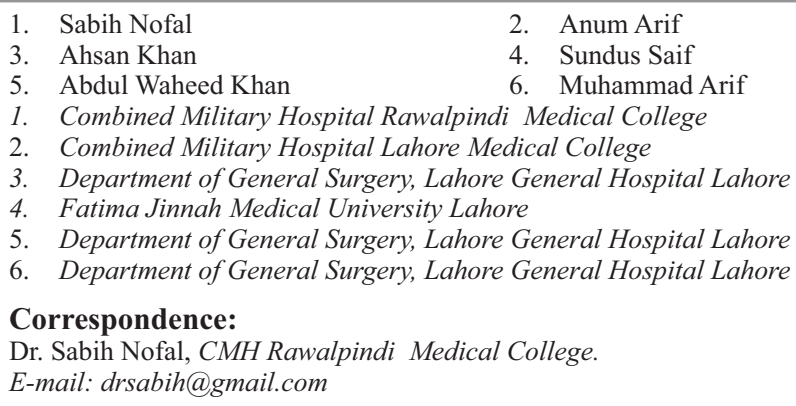

leakage. $^{1-2}$

The surgery of stoma reversal is generally done when the general conditions of medical recovers in patient. The surgery of stoma reversal might be caused the morbidities and complications like SSI (surgical site infection), postoperative ileus paralytic, bowel obstruction, anastomotic dehiscence and fistulas enterocutaneous. $^{3-5}$

The Surgical Site Infection is a very common and important morbidities that wound contamination at site is difficult to preventable. In past CPC (conventional primary closure) technique is the common method that used for the closure of skin in the surgery of stoma reversal with reported results that ranging from $3 \%$ to $43 \% .^{6-7} \mathrm{SSI}$ after following stoma reversal increase the wound risk of incisional hernia, dehiscence, ${ }^{8}$ health care costs and hospital stay length. ${ }^{9}$ 
To stop Surgical Site Infection after stoma reversal many techniques used that developed like implementation of gentamycin sponge subcutaneous, iodine wound irrigation, closing of wound by drain tube, late primary closure, secondary closure and string purse closure. $^{10-11}$

In 1997, Banargee ${ }^{12}$ firstlyreported a reliable, simple and cosmetically useful method of skin closure called as PSC (purse string closure). PSC method gives a small opening for the drainage of discharge of wound. This method also heal the wound rapidly than other method of wound healing or wound closure like primary delayed and secondary wound closure techniques.

In a study, it was concluded that, Surgical Site Infection was $36.67 \%$ in primary closure and $10 \%$ in Purse-string closure group. ${ }^{13}$ In another study, it was reported that, Surgical Site Infection occurred in $15.7 \%$ and was more frequent in the Primary Closure group than in the Purse-string closure group 21.4\% vs. $10 \%$. Time of hospital stay in the Purse-string closure group was shorter than it was in the Primary Closure group (14.79 days vs. 16.44 days). ${ }^{14}$ In another study, it was found that infection occurred in Pursestring closure patients $2.9 \%$ and in Primary Closure patients $21.8 \%$. Time of hospital stay in the Pursestring closure group was shorter than it was in the Primary Closure group (6.55 days vs. 6.78 days). ${ }^{15}$

\section{Hypothesis}

There is difference in Purse-string closure versus conventional primary closure in terms of less Surgical Site Infection and hospital stay for stoma reversal.

\section{Methods}

This Observational Study was conducted in Surgical Unit-III, Lahore General Hospital, Lahore. From January 5, 2018 to July 5, 2018. Patients were sampled via Non probability consecutive sampling. The sample size of 140 (70 in each group) cases was estimated by using $95 \%$ confidence level, $80 \%$ power of test with an expected percentage of surgical site infection in both groups with Purse-string closure $2.9 \%$ and conventional primary closure $21.8 \%{ }^{15}$ Surgical Site infection was defined as southhampton grade IV and $\mathrm{V}$.

Following patients were included in the study 1 . Patients of both gender 2. Patients ages between 25703 . Patients undergoing surgery for having ileosto- my for benign disease of intestine (as per operational definitions).

Following patients were excluded 1. Patients with pre-existing stomal site wound infection 2. Reversal of stoma through laparatomy 3. Post-operative anastomotic leak 4. Uremic patients 5. Patients on chemotherapy and radiations

After taking written informed consent, patients undergoing surgery for Ileostomy were randomly divided into two groups by computer generated lottery method, Group-A (Purse-string closure) and Group-B (Conventional primary closure). All operations were done by same surgical team.

In group A and B following method used like in A for the ileostomy reversal circular incision used with stitches of continuous and non-absorbable. The wound of skin was closed by using (Prolene No. 1) that leaving $0.5 \mathrm{~cm}$ defect on middle in the skin. In B for the ileostomy conventional incision used. Skin approximately resulting in linear scar.

When these assessments were made the patient were still admitted in hospital. Then all the patients were called for follow up checkup on $14^{\text {th }}$ days after operation and after one month. Both of the groups were checked and recorded for SSI after operation and hospital stay. All surgeries were done by the same surgical team to reduce bias. All the data and information were collected by proforma. The data was statistically analyzed by using SPSS v23.0. For the quantitative variables like age, hospital stay length mean and standard deviation were calculated. For qualitative variable like gender and SSI the frequency distribution and percentages were calculated. $t$ test (independent sample) used for the comparison of hospital stay mean. Chi-square was also used for the comparison of the frequencies of SSI. Data were stratified for gender and age. Respective tests of significance were applied post stratification. $p$-value $\leq 0.05$ was considered as significant.

\section{Results}

A total of 140 patients were enrolled for this study. Patients were divided into two groups i.e. Group-A (Purse-string closure) and Group-B (Conventional primary closure). In group-A, there were $41(58.6 \%)$ males and $29(41.4 \%)$ females, while in group-B, there were 39(55.7\%) males and 31(44.3\%) females. Mean age of group-A patients was $50.9 \pm 14.4$ years 
and $45.5 \pm 12.8$ years in group-B. In group-A, $18(25.7 \%)$ patients were in $25-40$ years age group, while $20(28.6 \%)$ and $32(45.7 \%)$ were in $41-55$ years and $>55$ years age groups respectively. In group-B, $28(40.0 \%)$ patients were in $25-40$ years age group, while $25(35.7 \%)$ and $17(24.3 \%)$ were in $41-55$ years and $>55$ years age groups respectively. In group-A, $26(37.1 \%)$ had normal weight, while $23(32.9 \%)$ and $21(30.0 \%)$ were overweight and obese respectively. In group-B, 21(30.0\%) had normal weight, while $24(34.3 \%)$ and $25(35.7 \%)$ were overweight and obese respectively. In group-A, mean duration of hospital stay was $5.7 \pm 1.0$ days, while $7.3 \pm 1$.1 days in group-B, which is statistically significant with a p-value of 0.000 . In group-A, surgical site infection was in $4(5.7 \%)$ patients, while $11(15.7 \%$ ) patients of group-B, which is statistically significant with a p-value of 0.046 .

\section{Discussion}

In this study significant results were found that a lower rate of SSI linked with PSC (purse string closure) when compared with CPC (conventional primary closure (CPC) $(5.7 \%$ vs. $15.7 \%, \mathrm{P}=0.046)$.

Our study results matched with two other recent studies that were also small and randomized controlled trials. ${ }^{16-17}$ Compared the PSC and CPC after stoma reversal. Reid et al. randomly allotted 61 ileostomy patients to either CPC and PSC and found a significant lower rate in Surgical Site Infection than PSC group $(6.7 \%$ vs. $38.7 \%, \mathrm{P}=0.005) .^{18}$

The estimated sample size of study was 60 patients and 66 was enrolled. The trial halted due to the overwhelming number in SSI than CPC group.

Camacho-Maurieset al. ${ }^{16}$ assigned randomly 61 patients with colostomies or ileostomies to CPC or PSC group. They find nill SSIs in PSC group aas compared with other group with $36.6 \%$ SSI rate in the CPC group $(\mathrm{P}<0.0001) .^{17}$

The estimates of sample size or the rates of SSI were not reported that used in the calculations. Surgical Site Infection rates in CPC group for both above mentioned studies were reported highest for this technique. $^{19}$

In present study the rate of Surgical Site Infection i.e. $15.7 \%$ in CPC group lies in middle range of previous studies reports ${ }^{18,20-21}$ with proper sample size and analysis of multivariate to handle potential confounders.

Our study also confirms the SSI rate in stoma site is more in CPC group than PSC group. Our results may be generalizable for all patients who undergo colostomy reversals or ileostomy.

The data of this study also matched with previously mentioned studies that includes controlled randomized trials also as other retrospective reviews and case control studies. ${ }^{22-23}$

In our study, all stoma Surgical Site Infection were managed bedside by opening the incision to allow the drainage of fluid. No stoma Surgical Site Infection needs antibiotic therapy additionally and reoperation. Similarly results are also find by Vermulst et al. ${ }^{24}$ in a study that all are manageable easily.

The biological process of wound healing consists of a series of complex interactions between cells, cytokines, and the extracellular matrix. Sometimes, the healing time is relatively long due to seroma formation.

The small orifice in the center of the wound allowed self drainage in the PSC group, so wound healing occurred more quickly due to less seroma formation. Murray et al. ${ }^{25}$ compared the patients of CPC with the patients of open wound retrospectively and find no increase in incisional hernias, hospital stay, fistula formation in between these two groups like SSI rate $36 \%$ in CL group.

In these and also in our study the follow up length not properly exclude the increasing incidence of hernias incisional that is known as SSI late complication.

In a study, it was concluded that, SSI was $36.67 \%$ in primary closure and $10 \%$ in Purse-string closure group. $^{13}$

In another study, it was reported that, Surgical Site Infection occurred in $15.7 \%$ and was more frequent in the Primary Closure group than in the Purse-string closure group $21.4 \%$ vs. $10 \%$. Time of hospital stay in the Purse-string closure group was shorter than it was in the Primary Closure group (14.79 days vs. 16.44 days). ${ }^{14}$

In another study, it was found that, infection occurred in Purse-string closure patients 2.9\% and in Primary Closure patients $21.8 \%$. Time of hospital stay in the Purse-string closure group was shorter than it was in the Primary Closure group (6.55 days vs. 6.78 days $){ }^{15}$

\section{Conclusion}

The frequency of surgical site infection and mean length of hospital stay after stoma reversal, pursestring suturing technique is significantly less than 
Table 1: Stratification of Surgical Site Infection in Both Groups with Respect to Gender

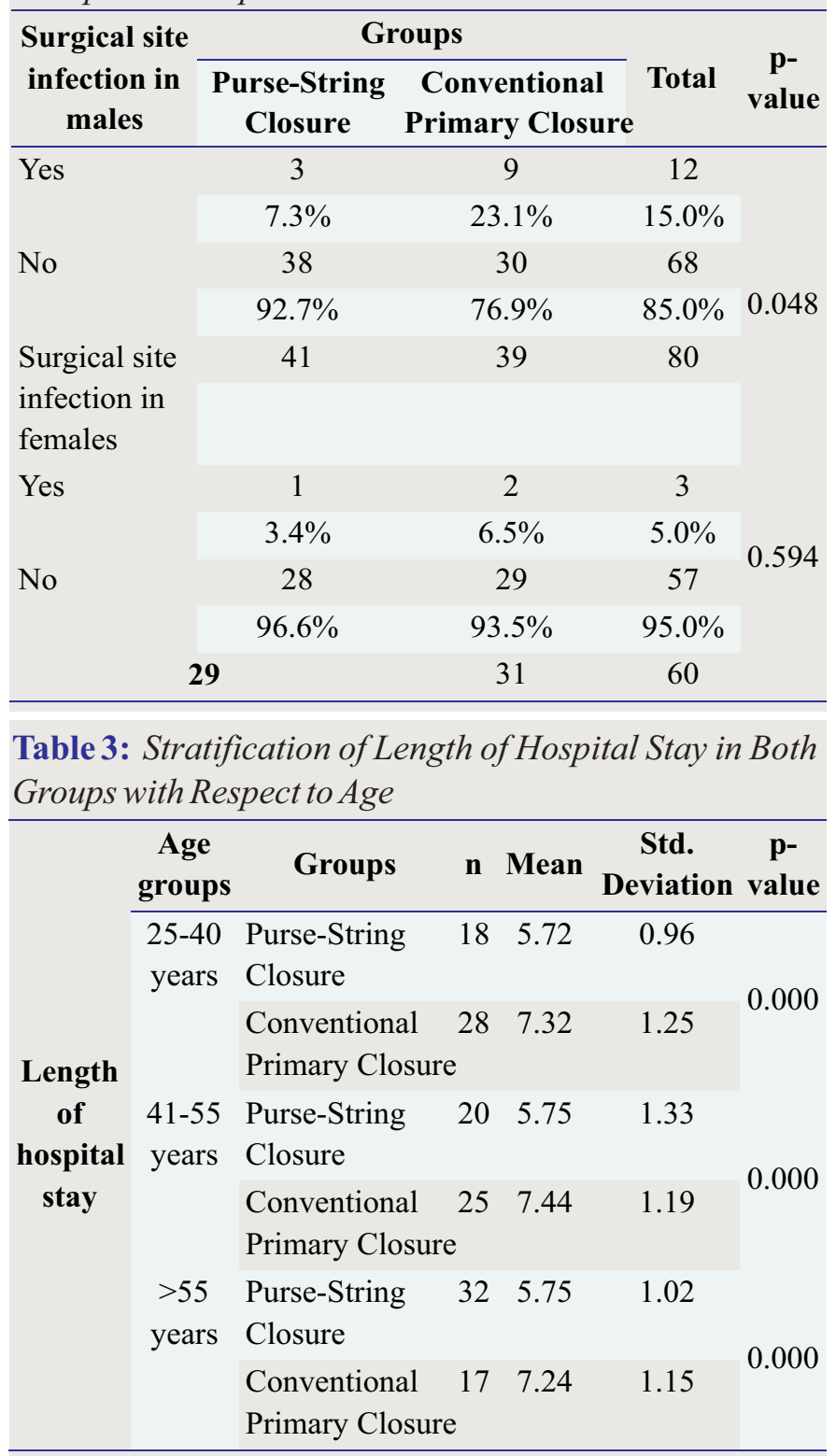

conventional primary closure technique.

\section{Conflict of Interest: None}

\section{References}

1. Mennigen R, Sewald W, Senninger N, Rijcken E. Morbidity of loop ileostomy closure after restorative proctocolectomy for ulcerative colitis and familial adenomatous polyposis: a systematic review. J Gastrointest Surg. 2014;18:2192-2200.

2. Li LT, Brahmbhatt R, Hicks SC, Davila JA, Berger $\mathrm{DH}$, Liang MK. Prevalence of surgical site infection at the stoma site following four skin closure techniques: a retrospective cohort study. Dig Surg. 2014; 31:73-78.

3. Murray BW, Cipher DJ, Pham T, Anthony T. The impact of surgical site infection on the development of incisional hernia and small bowel obstruction in
Table 1: Stratification of Surgical Site Infection in Both Groups with Respect to Gender

\begin{tabular}{|c|c|c|c|c|c|}
\hline \multirow[b]{2}{*}{$\begin{array}{l}\text { Age } \\
\text { groups }\end{array}$} & \multirow[b]{2}{*}{$\begin{array}{c}\text { Surgical } \\
\text { site } \\
\text { infection }\end{array}$} & \multicolumn{2}{|c|}{ Groups } & \multirow[b]{2}{*}{ Total } & \multirow[b]{2}{*}{$\begin{array}{c}\text { p- } \\
\text { value }\end{array}$} \\
\hline & & $\begin{array}{c}\text { Purse- } \\
\text { String } \\
\text { Closure }\end{array}$ & $\begin{array}{c}\text { Conventional } \\
\text { Primary } \\
\text { Closure } \\
\end{array}$ & & \\
\hline \multirow{6}{*}{$\begin{array}{l}25-40 \\
\text { years }\end{array}$} & \multirow[t]{2}{*}{ Yes } & 1 & 5 & 6 & \multirow{6}{*}{0.227} \\
\hline & & $5.6 \%$ & $17.9 \%$ & $13.0 \%$ & \\
\hline & \multirow[t]{2}{*}{ No } & 17 & 23 & 40 & \\
\hline & & $94.4 \%$ & $82.1 \%$ & $87.0 \%$ & \\
\hline & \multirow[t]{2}{*}{ Total } & 18 & 28 & 46 & \\
\hline & & $100.0 \%$ & $100.0 \%$ & $100.0 \%$ & \\
\hline \multirow{6}{*}{$\begin{array}{l}41-55 \\
\text { years }\end{array}$} & \multirow[t]{2}{*}{ Yes } & 2 & 4 & 6 & \multirow{6}{*}{0.556} \\
\hline & & $10.0 \%$ & $16.0 \%$ & $13.3 \%$ & \\
\hline & \multirow[t]{2}{*}{ No } & 18 & 21 & 39 & \\
\hline & & $90.0 \%$ & $84.0 \%$ & $86.7 \%$ & \\
\hline & \multirow[t]{2}{*}{ Total } & 20 & 25 & 45 & \\
\hline & & $100.0 \%$ & $100.0 \%$ & $100.0 \%$ & \\
\hline \multirow{6}{*}{$\begin{array}{l}>55 \\
\text { years }\end{array}$} & \multirow[t]{2}{*}{ Yes } & 1 & 2 & 3 & \multirow{6}{*}{0.230} \\
\hline & & $3.1 \%$ & $11.8 \%$ & $6.1 \%$ & \\
\hline & \multirow[t]{2}{*}{ No } & 31 & 15 & 46 & \\
\hline & & $96.9 \%$ & $88.2 \%$ & $93.9 \%$ & \\
\hline & \multirow[t]{2}{*}{ Total } & 32 & 17 & 49 & \\
\hline & & $100.0 \%$ & $100.0 \%$ & $100.0 \%$ & \\
\hline
\end{tabular}

colorectal surgery. Am J Surg. 2011;202:558-560.

4. Keenan JE, Speicher PJ, Thacker JK, Walter M, Kuchibhatla M, Mantyh CR. The preventive surgical site infection bundle in colorectal surgery: an effective approach to surgical site infection reduction and health care cost savings. JAMA Surg. 2014; 149: 1045-1052.

5. Higgins JP, Altman DG, Gøtzsche PC; Cochrane Bias Methods Group; Cochrane Statistical Methods Group. The Cochrane Collaboration's tool for assessing risk of bias in randomized trials. BMJ. 2011;343:5928.

6. Reid K, Pockney P, Pollitt T, Draganic B, Smith SR. Randomized clinical trial of short-term outcomes following purse-string versus conventional closure of ileostomy wounds. Br J Surg. 2010;97:1511-1517.

7. Dusch N, Goranova D, Herrle F, Niedergethmann M, Kienle P. Randomized controlled trial: comparison of two surgical techniques for closing the wound following ileostomy closure: purse string vs direct suture. Colorectal Dis. 2013;15:1033-1040.

8. Camacho-Mauries D, Rodriguez-Díaz JL, SalgadoNesme N, González QH, Vergara-Fernández O. Randomized clinical trial of intestinal ostomy takedown comparing pursestring wound closure vs conventional closure to eliminate the risk of wound infection. 
Dis Colon Rectum. 2013;56:205-211.

9. Lee JT, Marquez TT, Clerc D. Pursestring closure of the stoma site leads to fewer wound infections: results from a multicenter randomized controlled trial. Dis Colon Rectum. 2014;57:1282-1289.

10. Li LT , Hicks SC, Davila JA. Circular closure is associated with the lowest rate of surgical site infection following stoma reversal: a systematic review and multiple treatment metaanalysis. Colorectal Dis. 2014;16:406-416.

11. McCartan DP, Burke JP, Walsh SR, Coffey JC. Pursestring approximation is superior to primary skin closure following stoma reversal: a systematic review and meta-analysis. TechColoproctol. 2013;17: 345351.

12. Banerjee A. Pursestring skin closure after stoma reversal. Dis Colon Rectum. 1997;40:993-994.

13. Lodhi MFB, Javed F, Irfan S. Ileostomy Stoma Wound; Purse-string closure. Professional Med J 2015;22(6):833-837.

14. Yoon SI, Bae SM, Namgung H, Park DG. Clinical Trial on the Incidence of Wound Infection and Patient Satisfaction After Stoma Closure: Comparison of Two Skin Closure Techniques. Ann Coloproctol 2015; 31(1):29-33.

15. Alvandipour M, Gharedaghi B, Khodabakhsh H, Karami MY. Purse-String Versus Linear Conventional Skin Wound Closure of an Ileostomy: A Randomized Clinical Trial. Ann Coloproctol 2016; 32(4): 144-149.

16. Camacho-Mauries D, Rodriguez-Diaz JL, SalgadoNesme N, Gonzalez QH, Vergara-Fernandez O. Randomized clinical trial of intestinal ostomy takedown comparing pursestring wound closure vs conventional closure to eliminate the risk of wound infection. Dis Colon Rectum 2013;56:205-11.

17. Alexander JW, Solomkin JS, Edwards MJ. Updated recommenda $\neg$ tions for control of surgical site infections. Ann Surg 2011;253: 1082-93.

18. Reid K, Pockney P, Pollitt T, Draganic B, Smith SR. Randomized clinical trial of short-term outcomes following purse-string versus conventional closure of ileostomy wounds. British Journal of Surgery 2010; 97(10):1511-7.

19. Lahat G, Tulchinsky H, Goldman G, Klauzner JM, Rabau M. Wound infection after ileostomy closure: a prospective randomized study comparing primary vs. delayed primary closure techniques. Tech Coloproctol 2005;9:206-8.

20. Harold DM, Johnson EK, Rizzo JA, Steele SR. Primary closure of stoma site wounds after ostomy takedown. Am J Surg 2010;199: 621-4.

21. Lee JR, Kim YW, Sung JJ, Song OP, Kim HC, Lim $\mathrm{CW}$, et al. Con-ventional linear versus purse-string skin closure after loop ileostomy reversal: comparison of wound infection rates and operative outcomes. J Korean SocColoproctol 2011;27:58-63.

22. Li LT, Hicks SC, Davila JA, Kao LS, Berger RL, Arita NA, et al. Circular closure is associated with the lowest rate of surgical site infection following stoma reversal: a systematic review and multiple treatment meta-analysis. Colorectal Dis 2014;16:406-16.

23. McCartan DP, Burke JP, Walsh SR, Coffey JC. Pursestring ap-proximation is superior to primary skin closure following stoma reversal: a systematic review and meta-analysis. Tech Coloproctol 2013;17:34551.

24. Vermulst N, Vermeulen J, Hazebroek EJ, Coene PP, van der Harst E. Primary closure of the skin after stoma closure. Management of wound infections is easy without (long-term) complications. Dig Surg 2006; 23:255-8.

25. Murray BW, Cipher DJ, Pham T, Anthony T. The impact of surgi $\neg$ cal site infection on the development of incisional hernia and small bowel obstruction in colorectal surgery. Am J Surg 2011;202:558-60.

\section{Authors Contribution}

NS: Conceptionlization of Project

AA: Data Collection

KA: Literature Search

KWA: Drafting, Revision

AM: Writing of Manuscript 